\title{
Compartmental Analysis of Sodium Dynamics in Non-Edematous, Edematous and Uremic Patients
}

\author{
Takashi KinouaHI, M.D.
}

\section{SummaRY}

Compartmental analysis with $\mathrm{Na}^{24}$ has been carried out in 1) 16 subjects without edema, 2) 13 patients with edema, and 3) 5 uremic patients.

Three compartment parallel model was chosen as the most suitable model for the simulation of sodium metabolism in the human beings by trial and error. The first diffusion space of $\mathrm{Na}^{24}$, which was named the functional extracellular space averaged $17.9 \%$ of body weight in the nonedematous group. The total exchangeable sodium might be divided into I) the functional extracellular pool, 2) the rapidly exchangeable pool, and 3 ) the slowly exchangeable pool.

The functional extracellular space remained almost constant in edematous states, unless the renal function is markedly impaired. It is revealed that the increase of the slowly exchangeable pool in edematous state is most remarkable, and is suggested that formation of edema and ascites would serve as a reservoir to maintain the homeostasis of the most active part of the body.

\section{Additional Indexing Words:}

Plasma $\mathrm{Na}^{24}$ disappearance curve Functional extracellular space Rapidly exchangeable pool Slowly exchangeable pool Nonexchangeable pool Three compartment parallel model

7 HE investigation of sodium metabolism in the human beings is useful in many diseases, particularly in the edematous state. ${ }^{1)-13)}$ Edema is evidently one of the prominent manifestations of clinical abnormalities in sodium metabolism, although its mechanism regarding origin and maintenance remains still uncertain. ${ }^{14)-18)}$ In edematous state there is excessive retention of sodium and water, and also disorder in their distribution. ${ }^{1)-10), 12), 17), 18}$ (Therefore, sodium kinetics is especially fitted for studying it.

The aim of the present study is to define the alterations of sodium metabolism in several pathological states. Disorders in sodium dynamics may be revealed by the analysis of plasma $\mathrm{Na}^{24}$ disappearance curves, since they represent the summation of dynamic processes of sodium handling within the

From the First Department of Internal Medicine, Faculty of Medicine, University of Tokyo, Tokyo.

Received for publication March 19, 1971. 
body. ${ }^{19-21)}$ In order to examine such alterations, mathematical analysis of the plasma disappearance curves was performed in patients with various diseases.

On the basis of the findings obtained, a fundamental kinetic model for sodium metabolism was constructed and its biological validity was examined. After this, the kinetic parameters in physiological state were determined and they were compared with those in pathological states.

\section{Materials And Methods}

\section{A. Subjects}

The studies were carried out in 33 hospital inpatients, 21 males and 11 females. In 3 of them, a couple of measurements were done on the same subject.

The patients were divided into A, B, and C groups as follows (Table I). Group A was formed by 16 patients who had neither edema nor ascites. Two patients with idiopathic edema were also included into this group because they did not have edema at the time of measurements. In Group B were included 13 non-uremic patients with edema. Six of them had ascites, too. One patient with idiopathic edema included in this group is the same patient (N.T.) in group A. Five uremic patients, who were under treatment with hemodialysis or peritoneal dialysis, were included into Group C, because it was thought that they might represent a particular condition of body fluid metabolism.

\section{B. Procedures}

A solution of sodium chloride labeled with $\mathrm{Na}^{24}$ was injected quickly into the antecubital vein and the same amount of the solution was kept in a liter flask for use as a standard. The amount of $\mathrm{Na}^{24}$ injected in each subject ranged from 60 to $200 \mu \mathrm{Ci}$.

Specimens of blood were obtained serially at frequent intervals over a period of 24 hours. In a patient with ascites, specimens of ascitic fluid were also taken at the same intervals. Urine was collected serially up to 24 hours.

One or $2 \mathrm{ml}$. aliquots of plasma, ascitic fluid, urine and standard solution were transferred to polyethylene counting tubes and were counted in a well-type scintillation counter. Corrections for radioactive decay were made at the counting time.

Sodium concentrations of plasma, urine and ascitic fluid were estimated by a flame photometric method.

\section{Analysis of plasma disappearance curve for radioactive sodium}

The counts per min. per ml. of $\mathrm{Na}^{24}$ in plasma were plotted against time on a semilogarithmic graph, and a plasma disappearance curve for $\mathrm{Na}^{24}$ was obtained (Fig. 1). The curve could be analyzed graphically into 5 exponentials or more.

The radioactive tracer injected intravenously transferred very rapidly from the vascular pool into the neighboring phases, and the half-time of initial part of the plasma disappearance curve was very short. Therefore, it did not seem practical that the plasma space was treated as an independent compartment. 
Table I. Subjects Studied and Their Clinical Data

\begin{tabular}{|c|c|c|c|c|c|c|}
\hline Name & Age Sex & Diagnosis & B. W. (Kg.) & $\begin{array}{c}\mathrm{Na} \\
(\mathrm{mEq} / \mathrm{L} .)\end{array}$ & Edema & Ascites \\
\hline \multicolumn{7}{|l|}{ Group A } \\
\hline 1. S.Y. & $64 \mathrm{~F}$ & Osteoporosis & 40 & 145 & - & - \\
\hline 2. S. Y. & $64 \mathrm{~F}$ & Osteoporosis & 43.5 & 144 & - & - \\
\hline 3. T. U. & $51 \mathrm{M}$ & Coronary insufficiency & 54 & 144 & - & - \\
\hline 4. S. T. & $39 \mathrm{M}$ & Diabetes insipidus & 60 & 137 & - & - \\
\hline 5. Y.A. & $18 \mathrm{~F}$ & Obesity & 67 & 140 & - & - \\
\hline 6. M.Y. & $41 \mathrm{M}$ & Trauma & 55 & 139 & - & - \\
\hline 7. N. T. & $44 \mathrm{~F}$ & Idiopathic edema & 51 & 142 & - & - \\
\hline 8. M.S. & $34 \mathrm{~F}$ & Irritable colon & 38 & 144 & - & - \\
\hline 9. K. O. & $38 \mathrm{M}$ & Primary aldosteronism & 52 & 142 & - & - \\
\hline 10. S.S. & $38 \mathrm{M}$ & Addison's disease & 42 & 144 & - & - \\
\hline 11. S.S. & $38 \mathrm{M}$ & Addison's disease & 42 & 144 & - & - \\
\hline 12. T. N. & $30 \mathrm{~F}$ & Primary aldosteronism & 48 & 147 & $\cdots$ & - \\
\hline 13. Y.T. & $69 \mathrm{M}$ & Liver cirrhosis & 51 & 135 & - & - \\
\hline 14. N. H. & $31 \mathrm{M}$ & Sarcoidosis & 66 & 137 & - & - \\
\hline 15. G. T. & $22 \mathrm{M}$ & Chronic nephritis & 53 & 140 & - & - \\
\hline 16. A. I. & $24 \mathrm{M}$ & Nephrotic syndrome & 59 & 143 & - & - \\
\hline 17. T.S. & $28 \mathrm{M}$ & Nephrotic syndrome & 66.5 & 143 & - & - \\
\hline 18. A. A. & $22 \mathrm{~F}$ & Idiopathic edema & 38 & 148 & - & - \\
\hline \multicolumn{7}{|l|}{ Group B } \\
\hline 1. N.T. & $44 \mathrm{~F}$ & Idiopathic edema & 55.5 & 144 & + & - \\
\hline 2. T.S. & $46 \mathrm{M}$ & Acute liver atrophy & 53 & 138 & H & H \\
\hline 3. K. S. & $52 \mathrm{M}$ & Liver cirrhosis, hepatoma & 60 & 138 & $H$ & H \\
\hline 4. M.N. & $22 \mathrm{M}$ & Liver cirrhosis & 59.5 & 138 & H & H \\
\hline 5. M. A. & $52 \mathrm{~F}$ & Liver cirrhosis & 64 & 139 & + & $H$ \\
\hline 6. S. O. & $32 \mathrm{~F}$ & Hypothyroidism & 66.5 & 136 & \pm & - \\
\hline 7. H. K. & $53 \mathrm{~F}$ & Hypothyroidism & 62 & 142 & \pm & - \\
\hline 8. S. M. & $51 \mathrm{M}$ & Pulmonary cancer & 57 & 139 & + & - \\
\hline 9. K. I. & $59 \mathrm{M}$ & Reticulum cell sarcoma & 49 & 134 & + & - \\
\hline 10. K. S. & $63 \mathrm{M}$ & Congestive heart failure & 54 & 144 & H & + \\
\hline 11. S. M. & $46 \mathrm{M}$ & Hypertensive heart disease & 41 & 139 & + & - \\
\hline 12. T. T. & $48 \mathrm{M}$ & Nephrotic syndrome & 56 & 147 & H & + \\
\hline 13. T. K. & $20 \mathrm{M}$ & Chronic nephritis & 51 & 141 & + & - \\
\hline \multicolumn{7}{|l|}{ Group $\mathrm{C}$} \\
\hline 1. T. K. & $25 \mathrm{~F}$ & Uremia & 50 & 139 & - & - \\
\hline 2. Y.U. & $20 \mathrm{~F}$ & Uremia & 41 & 138 & $H$ & + \\
\hline 3. N. H. & $38 \mathrm{M}$ & Uremia & 54 & 139 & $H$ & + \\
\hline 4. K. N. & $44 \mathrm{M}$ & Uremia & 52 & 136 & $H$ & $H$ \\
\hline 5. S. U. & $24 \mathrm{M}$ & Uremia & 44.5 & 140 & $H$ & + \\
\hline
\end{tabular}




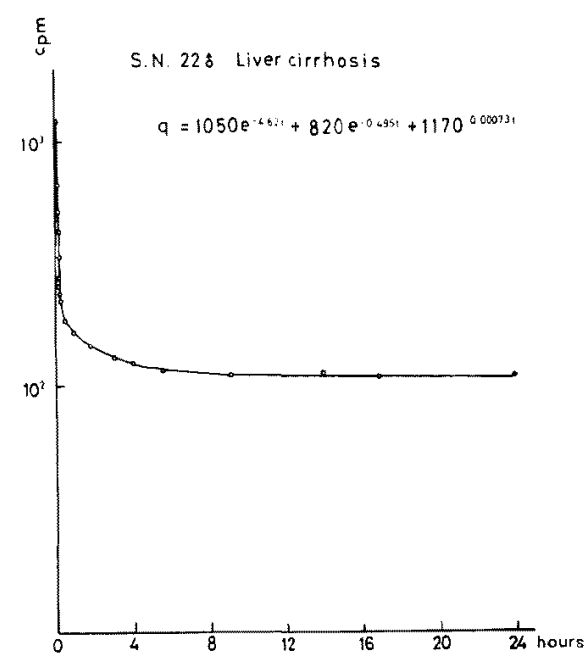

Fig. 1. A plasma disappearance curve for $\mathrm{Na}^{24}$. The curve was approximated by a sum of the 3 slowest exponentials.

After above considerations, the plasma disappearance curve was approximated by a sum of the 3 slowest exponentials in order to make the mathematical analysis simple. This approximation almost coincided with the observation except for a few minutes immediately after the injection of $\mathrm{Na}^{24}$. The plasma disappearance curve of the tracer will be represented by a sum of 3 exponentials as in the following equation,

$$
q=\mathrm{Ae}^{-\alpha t}+\mathrm{Be}^{-\beta \mathrm{t}}+\mathrm{Ce}^{-\gamma t}
$$

where $\mathrm{q}$ is the plasma $\mathrm{Na}^{24}$ concentration and $\mathrm{A}, \mathrm{B}, \mathrm{C}, \alpha, \beta$, and $\gamma$ are coefficients and exponents, respectively.

The first diffusion space of $\mathrm{Na}^{24}\left(V_{1}\right)$ can be calculated from the formula, ${ }^{201}$

$$
\mathrm{V}_{1}=\frac{\mathrm{I}}{\mathrm{A}+\mathrm{B}+\mathrm{C}}
$$

where $I$ is the total counts of $\mathrm{Na}^{24}$ injected. This space may represent a portion of the total extracellular water in which intravenously injected $\mathrm{Na}^{24}$ would be theoretically mixed instantaneously. In fact, this space averaged $17.9 \%$ of body weight in Group A. Therefore, it was named "functional extracellular space" with implications discussed below. ${ }^{22}$,

\section{Kinetic models and physiological consideration}

It is anticipated that a three-compartment model is suitable for the simulation of sodium metabolism in the human beings, as the plasma disappcarance curve can be adequately described by the sum of 3 exponentials.

Of several kinetic models containing 3 compartments, models which are biologically acceptable for analysis of sodium metabolism would be a series model and 
1. Parallel Models

a )

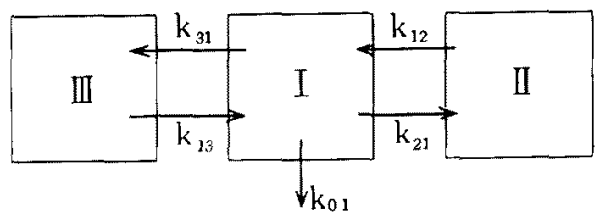

b )

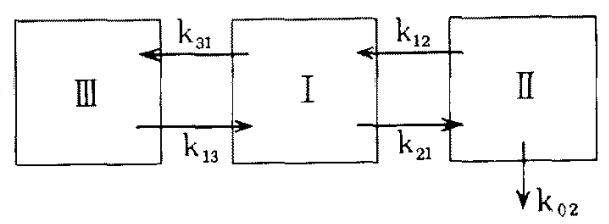

2. Series Mode

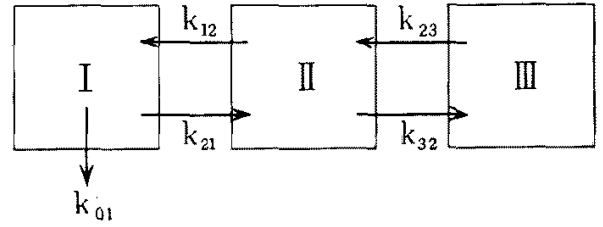

Fig. 2. Kinetic models which are biologically acceptable for analysis of sodium metabolism.

2 parallel models as shown in Fig. 2. One of the parallel models (Fig. 2 [b]) indicates a model in which the kidneys are assumed to comprise a compartment. However, calculated sodium content in compartment 2 by this model was much larger in quantity than the estimated content for sodium of the kidneys in the present experiments. This model does not seem reasonable for the simulation of sodium metabolism. Accordingly, it is considered that urine is excreted directly from compartment 1. The other models in Fig. 2 are also examined in order to choose the most suitable model for analysis.

In the parallel model indicated by a) in Fig. 2, the transport of $\mathrm{Na}^{24}$ into and out of each compartment may be described by the following differential equations, ${ }^{201,22)-25 \text { ) }}$

$$
\begin{aligned}
& \frac{\mathrm{dQ}_{1}}{\mathrm{dt}}=-\left(\mathrm{k}_{01}+\mathrm{k}_{21}+\mathrm{k}_{31}\right) Q_{1}+\mathrm{k}_{12} Q_{2}+\mathrm{k}_{13} \mathrm{Q}_{3} \\
& \frac{\mathrm{dQ_{2 }}}{\mathrm{dt}}=\mathrm{k}_{21} Q_{1}-\mathrm{k}_{12} \mathrm{Q}_{2} \\
& \frac{\mathrm{dQ_{3 }}}{\mathrm{dt}}=\mathrm{k}_{31} Q_{1}-\mathrm{k}_{13} Q_{3}
\end{aligned}
$$

where $Q_{i}$ is the amount of $\mathrm{Na}^{24}$ in compartment $i$, and $k_{i j}$ is the rate constant as described in Fig. 2.

In the same way, the series model will be described by the following cquations, ${ }^{201,22), 23), 25)}$ 


$$
\begin{aligned}
& \frac{d Q_{1}}{d t}=-\left(k_{01}+k_{21}\right) Q_{1}+k_{12} Q_{2} \\
& \frac{d Q_{2}}{d t}=k_{21} Q_{1}-\left(k_{32}+k_{12}\right) Q_{2}+k_{23} Q_{3} \\
& \frac{d Q_{3}}{d t}=k_{32} Q_{2}-k_{23} Q_{3}
\end{aligned}
$$

The general solution of those simultaneous differential equations would be of the type,

$$
Q_{1}=A_{1} e^{-\alpha t}+B_{1} e^{-s t}+C_{1} e^{-\gamma t}
$$

$Q_{1}\left(=q V_{1}\right)$ in the foregoing equation (5) is obtainable from the plasma $\mathrm{Na}^{24}$ disappearance curve (1) and the first diffusion space of $\mathrm{Na}^{24}$ (2). $\mathrm{A}_{1}, \mathrm{~B}_{1}, \mathrm{C}_{1}, \alpha, \beta$, and $\gamma$ are graphically also obtainable from the plasma $\mathrm{Na}^{24}$ disappearance curve. The remaining parameters defining kinetic models can be estimated by combining the above equations.

After a set of transfer constants for $\mathrm{Na}^{24}$ is thus determined, the values of $\mathrm{A}_{2}$, $\mathrm{B}_{2}, \mathrm{C}_{2}, \mathrm{~A}_{3}, \mathrm{~B}_{3}$, and $\mathrm{C}_{3}$ will be calculated by the following equations,

$$
\begin{aligned}
& \mathrm{A}_{2}=\frac{\mathrm{k}_{21}\left(-\alpha+\mathrm{k}_{33}\right)}{(-\alpha+\beta)(\gamma-\alpha)}\left(\mathrm{A}_{1}+\mathrm{B}_{1}+\mathrm{C}_{1}\right) \\
& \mathrm{B}_{2}=\frac{\mathrm{k}_{21}\left(-\beta+\mathrm{k}_{33}\right)}{(\alpha-\beta)(-\beta+\gamma)}\left(\mathrm{A}_{1}+\mathrm{B}_{1}+\mathrm{C}_{1}\right) \\
& \mathrm{C}_{2}=\frac{\mathrm{k}_{21}\left(-\gamma+\mathrm{k}_{33}\right)}{(-\gamma+\alpha)(\beta-\gamma)}\left(\mathrm{A}_{1}+\mathrm{B}_{1}+\mathrm{C}_{1}\right), \\
& \mathrm{A}_{3}=\frac{\mathrm{k}_{31}\left(-\alpha+\mathrm{k}_{22}\right)}{(-\alpha+\beta)(\gamma-\alpha)}\left(\mathrm{A}_{1}+\mathrm{B}_{1}+\mathrm{C}_{1}\right) \\
& \mathrm{B}_{3}=\frac{\mathrm{k}_{31}\left(-\beta+\mathrm{k}_{22}\right)}{(\alpha-\beta)(-\beta+\gamma)}\left(\mathrm{A}_{1}+\mathrm{B}_{1}+\mathrm{C}_{1}\right) \\
& \mathrm{C}_{3}=\frac{\mathrm{k}_{31}\left(-\gamma+\mathrm{k}_{22}\right)}{(-\gamma+\alpha)(\beta-\gamma)}\left(\mathrm{A}_{1}+\mathrm{B}_{1}+\mathrm{C}_{1}\right),
\end{aligned}
$$

where $\mathrm{k}_{\mathrm{ii}}$ shows the sum of transfer constants for $\mathrm{Na}^{24}$ leaving compartment $\mathrm{i}$. Therefore, the theoretical equations expressing total radioactivities in compartment 2 and $3\left(Q_{2}\right.$ and $\left.Q_{3}\right)$ can be obtained. In Fig. 3, the theoretical curves for $\mathrm{Na}^{24}$ activities in compartment 2 and 3 is shown corresponding to the series and the parallel model, respectively. In both models, the theoretical curves in the remotest compartment 3 resemble closely each other the $\mathrm{Na}^{24}$ concentration curves in ascitic fluid as shown in Fig. 4. It is, therefore, assumed that ascitic fluid is included in compartment 3 .

It is considered that the pathogenetic factors in ascites formation are, e.g., an increase in portal venous pressure, decreased oncotic pressure of the plasma, and increased capillary permeability. $\left.\left.\left.\left.{ }^{17}\right), 18\right), 26\right), 27\right)$ In the series model, compartment 2 is located between the "functional extracellular space" and compartment 3 containing ascitic fluid. However, compartment 3 should have direct contact with the functional extracellular space, since it is unthinkable that all residual extracellular 

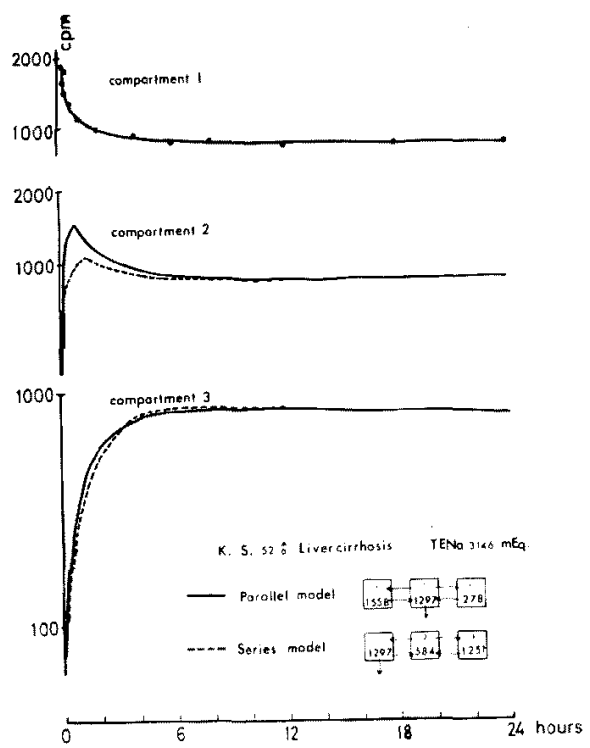

Fig. 3. The theoretical curves for $\mathrm{Na}^{24}$ activities in compartment 2 and 3 corresponding to the serics and the parallel models.

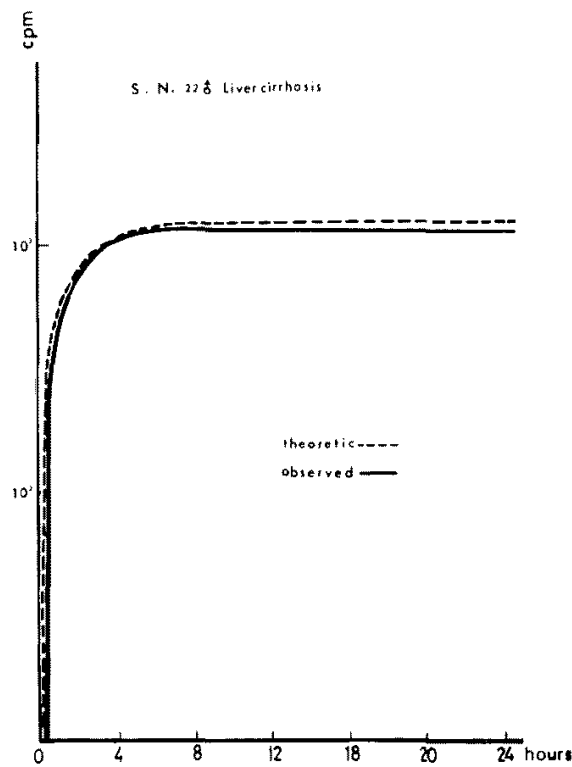

Fig. 4. The $\mathrm{Na}^{24}$ concentration curve in ascitic fluid.

water exists between the "functional extracellular space" and ascitic fluid. It is concluded that the three compartment parallel model will apply most appropriately for the analysis of sodium kinetics in the human beings.

Transfer constants of $\mathrm{Na}^{24}$ in this model (Table II) are obtained as follows:25) First, when $\mathrm{X}_{1}, \mathrm{X}_{2}$, and $\mathrm{X}_{3}$ are defined by the following equations, 
Table II. Kinetics Data (1), the Transfer Rate Constants of $\mathrm{Na}^{24}$

\begin{tabular}{|c|c|c|c|c|c|c|}
\hline & $k_{12}$ & $k_{21}$ & $\mathrm{k}_{18}$ & $k_{31}$ & $\mathbf{k}_{01}$ & $k_{01}{ }^{11]}$ \\
\hline \multicolumn{7}{|c|}{ Group A } \\
\hline 1. & 3.997 & 1.294 & 0.402 & 0.211 & 0.0094 & 0.0072 \\
\hline 2. & 3.892 & 1.021 & 0.340 & 0.157 & 0.0061 & 0.0051 \\
\hline 3. & 4.699 & 1.653 & 0.234 & 0.129 & 0.0100 & 0.0074 \\
\hline 4. & 2.176 & 1.079 & 0.258 & 0.113 & 0.0069 & 0.0050 \\
\hline 5. & 2.431 & 0.554 & 0.410 & 0.109 & 0.0061 & 0.0053 \\
\hline 6. & 4.838 & 0.910 & 0.421 & 0.178 & 0.0039 & 0.0041 \\
\hline 7. & 3.422 & 1.132 & 0.442 & 0.224 & 0.0088 & 0.0064 \\
\hline 8. & 6.019 & 1.627 & 0.467 & 0.223 & 0.0059 & 0.0049 \\
\hline 9. & 2.421 & 0.565 & 0.294 & 0.116 & 0.0042 & 0.0086 \\
\hline 10. & 6.413 & 1.863 & 0.619 & 0.286 & 0.0103 & 0.0077 \\
\hline 11. & 3.239 & 1.030 & 0.380 & 0.191 & 0.0077 & \\
\hline 12. & 3.352 & 1.187 & 0.423 & 0.264 & 0.0071 & 0.0044 \\
\hline 13. & 3.573 & 1.294 & 0.364 & 0.270 & 0.0070 & 0.0043 \\
\hline 14. & 3.042 & 1.187 & 0.321 & 0.309 & 0.0081 & 0.0076 \\
\hline 15. & 3.379 & 1.182 & 0.393 & 0.197 & 0.0054 & 0.0049 \\
\hline 16. & 2.796 & 1.277 & 0.191 & 0.124 & 0.0042 & 0.0044 \\
\hline 17. & 1.965 & 0.313 & 0.341 & 0.155 & 0.0022 & 0.0023 \\
\hline 18. & 1.776 & 0.426 & 0.227 & 0.125 & 0.0096 & 0.0076 \\
\hline \multicolumn{7}{|c|}{ Group B } \\
\hline 1. & 2.524 & 1.107 & 0.249 & 0.076 & 0.0040 & 0.0037 \\
\hline 2. & 4.427 & 1.820 & 0.267 & 0.215 & 0.0062 & 0.0029 \\
\hline 3. & 3.762 & 0.807 & 0.321 & 0.386 & 0.0049 & 0.0022 \\
\hline 4. & 3.102 & 1.404 & 0.324 & 0.384 & 0.0019 & 0.0006 \\
\hline 5. & 3.433 & 0.617 & 0.339 & 0.166 & 0.0074 & 0.0043 \\
\hline 6. & 3.780 & 0.776 & 0.507 & 0.307 & 0.0080 & 0.0045 \\
\hline 7. & 2.542 & 0.967 & 0.335 & 0.203 & 0.0013 & 0.0023 \\
\hline 8. & 3.761 & 1.499 & 0.347 & 0.212 & 0.0070 & 0.0079 \\
\hline 9. & 6.255 & 3.509 & 0.467 & 0.365 & 0.0098 & 0.0096 \\
\hline 10. & 2.791 & 2.404 & 0.321 & 0.257 & 0.0071 & \\
\hline 11. & 5.609 & 1.983 & 0.723 & 0.392 & 0.0087 & 0.0081 \\
\hline 12. & 2.187 & 1.506 & 0.288 & 0.071 & 0.0029 & 0.0022 \\
\hline 13. & 5.622 & 2.000 & 0.704 & 0.273 & 0.0040 & 0.0031 \\
\hline \multicolumn{7}{|c|}{ Group C } \\
\hline 1. & 8.156 & 1.784 & 0.405 & 0.209 & 0.0086 & 0.0011 \\
\hline 2. & 4.890 & 0.828 & 0.538 & 0.356 & 0.0055 & 0.0001 \\
\hline 3. & 11.128 & 2.715 & 0.675 & 0.268 & 0.0066 & 0.0000 \\
\hline 4. & 8.590 & 1.670 & 0.909 & 0.432 & 0.0006 & 0.0008 \\
\hline 5. & 5.643 & 1.221 & 0.633 & 0.320 & 0.0008 & 0.0001 \\
\hline
\end{tabular}




$$
\begin{aligned}
\frac{\mathrm{A}(\beta+\gamma)+\mathrm{B}(\alpha+\gamma)+\mathrm{C}(\alpha+\beta)}{\mathrm{A}+\mathrm{B}+\mathrm{C}} & =\mathrm{X}_{1} \\
\frac{\mathrm{A} \cdot \beta \gamma+\mathrm{B} \cdot \alpha \beta+\mathrm{C} \cdot \alpha \beta}{\mathrm{A}+\mathrm{B}+\mathrm{C}} & =\mathrm{X}_{2} \\
\frac{\mathrm{A} \cdot \alpha+\mathrm{B} \cdot \beta+\mathrm{C} \cdot \gamma}{\mathrm{A}+\mathrm{B}+\mathrm{C}} & =\mathrm{X}_{3},
\end{aligned}
$$

and we have,

$$
\begin{aligned}
& \mathrm{k}_{12}=\frac{\mathrm{X}_{1}+\sqrt{\mathrm{X}_{1}^{2}-4 \mathrm{X}_{2}}}{2} \\
& \mathrm{k}_{13}=\frac{\mathrm{X}_{1}-\sqrt{\mathrm{X}_{1}^{2}-4 \mathrm{X}_{2}}}{2} \\
& \mathrm{k}_{01}=\frac{\alpha \beta \gamma}{\mathrm{X}_{2}}
\end{aligned}
$$

Then, $k_{31}$ and $k_{21}$ will be obtained by the following formulas,

$$
\begin{aligned}
& k_{31}=\frac{k_{12} X_{4}-X_{5}}{k_{12}-k_{13}} \\
& k_{21}=X_{4}-k_{31},
\end{aligned}
$$

in which,

$$
\begin{aligned}
& \mathrm{X}_{4}=\mathrm{X}_{9}-\mathrm{k}_{01} \\
& \mathrm{X}_{5}=\left(\mathrm{X}_{3} \mathrm{X}_{1}+\mathrm{X}_{2}\right)-(\alpha \beta+\beta \gamma+\gamma \alpha) .
\end{aligned}
$$

If we designate the amount of non-radioactive sodium in compartment $i$ with the symbol $S_{1}, S_{1}$ will be obtained by the product of the volume of compartment 1 $\left(V_{1}\right)$ and the plasma sodium concentration.

When the system is in steady state, the flow of sodium into and out of each compartment may be constant.

Therefore,

$$
\begin{aligned}
& \mathrm{S}_{2}=\mathrm{k}_{21} / \mathbf{k}_{12} \cdot \mathrm{S}_{1} \\
& \mathrm{~S}_{3}=\mathrm{k}_{31} / \mathbf{k}_{13} \cdot \mathrm{S}_{1} .
\end{aligned}
$$

$\Sigma \mathrm{S}\left(=\mathrm{S}_{1}+\mathrm{S}_{2}+\mathrm{S}_{3}\right)$ indicates the total sodium content in 3 compartments, and it is thought to be equal to the total exchangeable sodium calculated by the dilution principle (Table III).

It is, therefore, necessary in kinetic studies on sodium metabolism to divide the total exchangeable sodium into 3 categories as follows;

1) The functional extracellular pool

2) The rapidly exchangeable pool

3) The slowly exchangeable pool

The rate constant $k_{01}$ is the fractional flux coefficient for loss of $\mathrm{Na}^{24}$ from compartment 1 by irreversible processes, and is reflected in the urinary excretion, the extrarenal excretion, such as the fecal and perspiratory loss, and the diffusion to the non-exchangeable pool, namely to a certain part of the human body which 
Table III. Kinetics Data (2), the Functional Extracellular Space, Sodium Space and Total Exchangeable Sodium

\begin{tabular}{|c|c|c|c|c|c|c|c|}
\hline & L. (\%) & $\begin{array}{c}\text { Na space } \\
\text { L. }(\%)\end{array}$ & $\left|\begin{array}{c}\text { TENa mEq. } \\
(\mathrm{mEq} . / \mathrm{Kg} .)\end{array}\right|$ & $\sum \mathrm{S}$ & $S_{1}$ & $\mathrm{~S}_{2}$ & $\mathbf{S}_{\mathbf{3}}$ \\
\hline \multicolumn{8}{|l|}{ Group A } \\
\hline 1. & $7.4(18.5)$ & $14.3(35.8)$ & $2074(51.9)$ & $1983(49.6)$ & $1073(26.8)$ & $347(8.7)$ & $563(14.1)$ \\
\hline 2. & $8.5(19.5)$ & $14.8(34.0)$ & $2131(49.0)$ & $2110(48.5)$ & $1224(28.1)$ & $321(7.4)$ & $565(13.0)$ \\
\hline 3. & $9.2(17.0)$ & $17.7(32.8)$ & $2545(47.1)$ & $2472(45.8)$ & $1325(24.5)$ & $466(8.6)$ & $681(12.6)$ \\
\hline 4. & $9.0(15.0)$ & $17.7(29.5)$ & $2425(40.4)$ & $2384(39.7)$ & $1233(20.6)$ & $611(10.2)$ & $540(9.0)$ \\
\hline 5. & $12.6(18.8)$ & $19.8(29.6)$ & $2772(41.4)$ & $2635(39.3)$ & $1764(26.3)$ & $402(6.0)$ & $462(6.0)$ \\
\hline 6. & $2(20.4)$ & $18.3(33.3)$ & $2544(46.3)$ & $2507(45.6)$ & $1556(28.3)$ & $293(5.3)$ & $659(12.0)$ \\
\hline 7. & $10.1(19.8)$ & $18.9(36.7)$ & $2684(52.6)$ & $2681(52.6)$ & $1434(28.1)$ & $474(9.3)$ & $727(14.3)$ \\
\hline 8. & $6.9(19.7)$ & $12.2(34.9)$ & $1750(50.0)$ & $1718(49.1)$ & $994(28.4)$ & $269(7.7)$ & 455 \\
\hline 9. & 9.8 & $16.0(30.8)$ & $2270(43.7)$ & $2265(43.6)$ & $1392(26.8)$ & $324(6.2)$ & $549(10.6)$ \\
\hline 10. & 9.0( & $15.9(36.2)$ & $2290(54.5)$ & $2272(54.1)$ & $1296(30.9)$ & $376(9.0)$ & $600(14.3)$ \\
\hline 11. & 8.9 & $16.1(38.4)$ & $2308(55.0)$ & $2270(54.0)$ & $1247(29.7)$ & $397(9.5)$ & $626(14.9)$ \\
\hline 12. & 7.4 & $14.6(30.4)$ & $2146(44.7)$ & $2124(44.3)$ & $1073(22.4)$ & $380(7.9)$ & $.0)$ \\
\hline 13. & $9.3(18.2)$ & $19.8(38.4)$ & $2673(52,4)$ & $2645(51.9)$ & $1256(24.6)$ & $455(8.9)$ & 934 \\
\hline 14. & $7.2(11.0)$ & $17.2(26.0)$ & $2356(35.7)$ & $2330(35.3)$ & $991(15.0)$ & $387(5.9)$ & $952(14.4)$ \\
\hline 15. & $9.0(17.0)$ & $16.4(31.0)$ & $2296(43.3)$ & $2333(43.2)$ & $1260(23.8)$ & $441(8.3)$ & 632 \\
\hline 16. & $7.9(13.4)$ & $16.8(28.5)$ & $2402(40.7)$ & $2379(40.3)$ & 1130 & $516(8.8)$ & $733(12.4)$ \\
\hline 17. & $11.0(16.6)$ & $17.8(26.9)$ & $(38,5)$ & $2534(38.7)$ & 1570 & $250(3.8)$ & \\
\hline 18. & $7.4(19.5)$ & $12.9(33.9)$ & $1920(50.5)$ & $1870(49.2)$ & $1100(28.9)$ & $264(6.9)$ & $606(15.9)$ \\
\hline & & $(32.6)$ & & & & $387(7.7)$ & \\
\hline S. D. & $(2,7)$ & (3.6) & $263(5.6)$ & $260(5.5)$ & $204(4.0)$ & $93(1.6)$ & $130(2.5)$ \\
\hline \multicolumn{8}{|l|}{ Group B } \\
\hline 1. & $11.9(20.1)$ & $20.8(37.5)$ & $2995(54.0)$ & $2989(53.8)$ & $1714(30.9)$ & $752(13.5)$ & $523(9.4)$ \\
\hline 2. & $9.5(18.0)$ & $22.0(41.5)$ & $3036(57.0)$ & $2908(55.0)$ & $1312(24.8)$ & $540(10.2)$ & $1051(19.8)$ \\
\hline 3. & $9.4(15.6)$ & $22.8(38.0)$ & $3146(52,4)$ & $3133(52.1)$ & $1297(21.6)$ & $278(4.6)$ & $1558(25.9)$ \\
\hline 4. & $13.2(22.2)$ & $34.2(57.4)$ & $4720(79.3)$ & $4692(78.9)$ & $1820(30.5)$ & $822(13.8)$ & $2050(34.3)$ \\
\hline 5. & $14.1(22.0)$ & $23.7(37.0)$ & $3294(51.5)$ & $3270(51.1)$ & $1960(30.6)$ & $352(5.4)$ & $958(14.9)$ \\
\hline 6. & $9.8(14.7)$ & $17.8(26.8)$ & $2420(36.5)$ & $2412(36.3)$ & $1333(20.0)$ & $272(4.1)$ & $807(11.2)$ \\
\hline 7. & $11.6(18.7)$ & $22.1(35.6)$ & $3138(51.0)$ & $3151(50.8)$ & $1647(26.6)$ & $562(9.1)$ & $942(15.2)$ \\
\hline 8. & $10.5(18.4)$ & $21.3(37.5)$ & $2961(52,0)$ & $2935(51.5)$ & $1460(26.0)$ & $583(10.1)$ & $893(15.7)$ \\
\hline 9. & $9.9(20.2)$ & $25.5(49.9)$ & $3150(64,2)$ & $3108(63.4)$ & $1327(27.2)$ & $744(15.2)$ & $1037(21.0)$ \\
\hline 10. & $10.5(19.4)$ & $28.0(51.9)$ & $4050(75,0)$ & $4019(74.4)$ & $1512(28.0)$ & $1302(24.2)$ & $1205(22.4)$ \\
\hline 11. & & $15.2(37.0)$ & $2120(51.6)$ & $2081(50.8)$ & $1098(26.8)$ & $388(9.5)$ & $595(14.5)$ \\
\hline 12. & $13.8(24,6)$ & $26.8(48.0)$ & $3940(70.4)$ & $3926(70.1)$ & $2029(36.2)$ & $1397(25.0)$ & $500(8.9)$ \\
\hline 13. & $11.1(21.8)$ & $19.5(38.2)$ & $2750(54.0)$ & $2728(53.5)$ & $1565(30.7)$ & $557(10.9)$ & $606(11.9)$ \\
\hline & & $(41.3)$ & $3209(57.6)$ & 318 & $1544(27.7)$ & & \\
\hline S. D. & $(3.8)$ & $(7.9)$ & $662(11.2)$ & $664(11.2)$ & $267(4.1)$ & $340(6.3)$ & $421(7.0)$ \\
\hline
\end{tabular}


Table III. Continued

\begin{tabular}{c|r|r|r|r|r|r|r}
\hline & $\begin{array}{c}\text { ECF } \\
\text { L. (\%) }\end{array}$ & $\begin{array}{c}\text { Na space } \\
\text { L. (\%) }\end{array}$ & $\begin{array}{c}\text { TENa mEq. } \\
(\mathrm{mEq} . / \mathrm{Kg} .)\end{array}$ & $\sum \mathrm{S}$ & $\mathrm{S}_{1}$ & $\mathrm{~S}_{2}$ & \multicolumn{1}{|c|}{$\mathrm{S}_{8}$} \\
\hline $\begin{array}{c}\text { Group C } \\
\text { I. }\end{array}$ & $11.1(22.2)$ & $19.2(38.4)$ & $2652(53.0)$ & $2632(52.6)$ & $1526(30.5)$ & $320(6.4)$ & $786(15.6)$ \\
2. & $13.1(32.0)$ & $24.1(58.8)$ & $3326(81.1)$ & $3309(80.7)$ & $1808(44.1)$ & $306(7.5)$ & $1195(29.0)$ \\
3. & $15.6(28.9)$ & $25.9(48.0)$ & $3600(66.7)$ & $3580(66.3)$ & $2168(40.1)$ & $529(9.8)$ & $883(16.4)$ \\
4. & $16.6(31.9)$ & $27.7(53.3)$ & $3767(72.4)$ & $3769(72.5)$ & $2258(59.9)$ & $439(11.6)$ & $1072(28.4)$ \\
5. & $14.2(31.9)$ & $24.4(54.8)$ & $3416(76.8)$ & $3422(76.9)$ & $1988(44.7)$ & $430(9.7)$ & $1004(22.4)$ \\
\hline Mean & $(29.4)$ & $(50.7)$ & $3352(70.0)$ & $3342(69.8)$ & $1950(43.9)$ & $405(9.0)$ & $988(22.4)$ \\
S.D. & $(3.8)$ & $(7.0)$ & $382(9.8)$ & $387(9.8)$ & $262(9.5)$ & $83(1.8)$ & $143(5.7)$
\end{tabular}

has negligibly small fractional efflux rate.

If the transfer constant for the urinary $\mathrm{Na}^{24}$ excretion and the amount of $\mathrm{Na}^{24}$ eliminated in the urine till time $t$ are indicated with $k_{01}{ }^{u}$ ) and $U$, respectively, $k_{01}{ }^{u}$ can be calculated by the following equation,

$$
\mathrm{U}=\int_{0}^{\mathrm{t}} \mathrm{k}_{01}{ }^{\mathrm{w}} \cdot \mathrm{Q}_{1} \mathrm{dt}
$$

The calculated values of $k_{01}{ }^{u}$ ) for all cases are close to those of $k_{01}$ with a few exceptions (Table II). It is, therefore, inferred that the extremely small quantity of $\mathrm{Na}^{24}$ usually escapes by extrarenal routes and diffuses into the non-exchangeable pool.

\section{RESULTS}

\section{A. Plasma disappearance curve}

The mean plasma $\mathrm{Na}^{24}$ concentrations, expressed in percentage of the total injected dose, were plotted against time on semilogarithmic graph (Fig. 5).

The values in Group B and C were significantly lower than those in Group A over the whole period of observation. Therefore, it was inferred that the sodium space was increased in edematous and uremic patients. The values in Group C seemed to be smaller than those in Group B, but the difference was not significant. The shapes of plasma disappearance curves resembled relatively each other in all groups. However, the intial rate of decline of the curve was slower in the uremic group than in the other 2 groups.

\section{B. Sodium space}

Since the amount of $\mathrm{Na}^{24}$ retained in the body may be approximated by the difference between the total injected dose and the amount of $\mathrm{Na}^{24}$ excreted in the urine, the sodium space, namely the distribution volume of $\mathrm{Na}^{24}$, can 


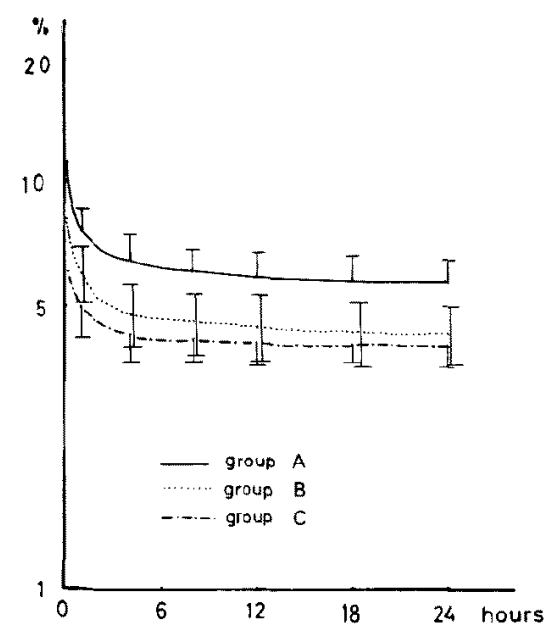

Fig. 5. The mean plasma $\mathbf{N a}^{24}$ concentration curves in Group $\mathbf{A}, \mathbf{B}$ and C, expressed in the percentage of the total injected dose.

be determined by dividing the amount retained in the body by plasma $\mathrm{Na}^{24}$ concentration at any time.

The apparent sodium spaces at every blood sampling moments were calculated and averaged for each group (Fig. 6). The sodium spaces expanded very quickly during the first 2 or 3 hours, then more slowly from 4 to 10 hours, and insignificantly after about 12 hours.

The time course curves of the sodium spaces in both edematous and uremic groups were qualitatively similar to that of normal group, but it was evident that the sizes of the sodium spaces in Group B and C were greater than in Group A during the whole period.

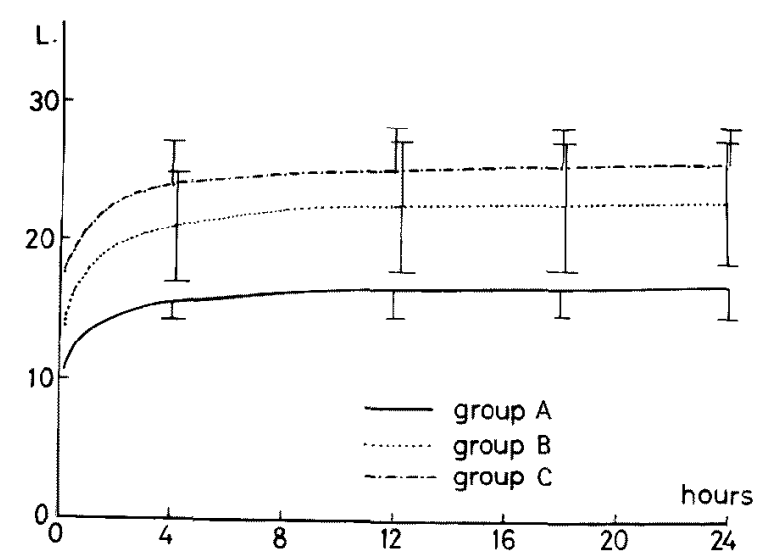

Fig. 6. The curves of the mean apparent volume of $\mathrm{Na}^{24}$ distribution for each group. 
The mean values of the sodium spaces calculated by the extrapolation method from the slopes at 24 hours for Group A, B, and C were, respectively, $16.5 \pm 2.1$ L. (Mean \pm S.D.), $23.1 \pm 4.7$ L., and $24.3 \pm 2.8 \mathrm{~L}$. (Table II). It was, therefore, considered that the sodium spaces at 24 hours were increased approximately by 40 to $50 \%$ in the edematous and uremic groups in comparison with the non-edematous group. The absolute values of sodium space were not significantly different between Group B and Group C. However, expressed as the percentage of body weight, the 24 hour sodium spaces for Group $\mathrm{A}, \mathrm{B}$, and $\mathrm{C}$ were $32.6 \pm 3.6 \%, 41.3 \pm 7.9 \%$, and $50.7 \pm 7.0 \%$, respectively, and the increase in the sodium space was relatively greater in Group $C$ than in Group B ( $p<0.05)$.

\section{Urinary excretion rate of $\mathrm{Na}^{24}$}

Fig. 7 demonstrates the mean cumulative curves of the urinary $\mathrm{Na}^{24}$ excretion, expressed as percentage of the total injected amount. The mean 24 hour urinary $\mathrm{Na}^{24}$ excretions for Group $\mathrm{A}, \mathrm{B}$, and $\mathrm{C}$ were $7.4 \pm 2.1 \%, 5.1 \pm 2.3 \%$, and $0.6 \pm 0.6 \%$ of the total injected dose, respectively. As expected, the excretion of $\mathrm{Na}^{24}$ was markedly reduced in the uremic group. The 24 hour urinary excretion, or daily turnover rates, in patients with edema were $6 \%$ or less of the total injected dose with a few exceptions.

Although the daily turnover rates of sodium were relaiively decreased in

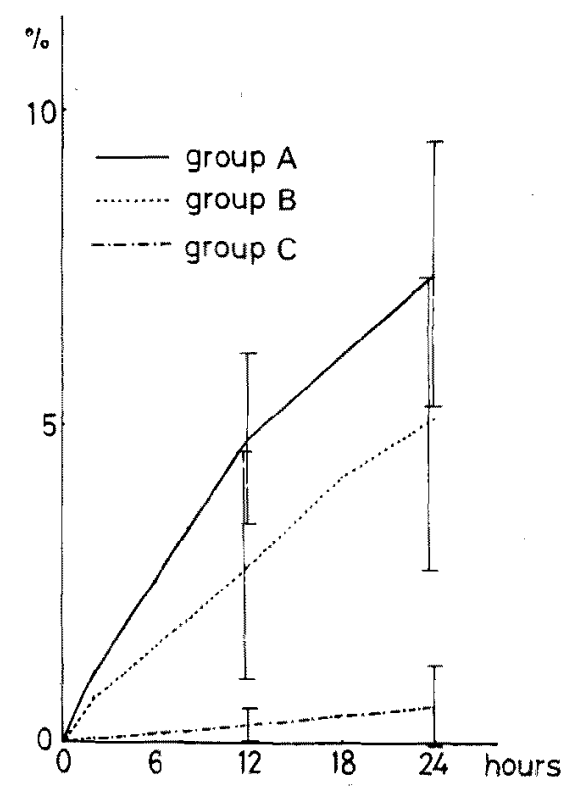

Fig. 7. The mean cumulative curves of the urinary $\mathrm{Na}^{24}$ excretion for each group. 
edematous subjects, the total exchangeable sodium was increased and the dietary sodium intake was reduced in these patients.

\section{Total exchangeable sodium}

The mean total exchangeable sodium calculated by multiplying the sodium space, which was estimated by extrapolation method from the slopes at 24 hours, by the plasma sodium concentration for Group A, B, and C were $2,341 \pm 263 \mathrm{mEq}$., $3,209 \pm 662 \mathrm{mEq}$., and 3,352 $\pm 382 \mathrm{mEq}$., respectively (Table III).

The amount of total exchangeable sodium was significantly greater in Group B and $\mathrm{C}$ than in Group A ( $\mathrm{p}>0.01)$. The difference between Group B and $C$ was not statistically significant $(p>0.1)$. However, when the total exchangeable sodium was expressed as the ratio of body weight, the mean value for Group A was $46.5 \pm 5.6 \mathrm{mEq} . / \mathrm{Kg}$, whereas those for Group B and C were respectively $57.6 \pm 11.2 \mathrm{mEq} . / \mathrm{Kg}$. and $70.0 \pm 9.8 \mathrm{mEq} . / \mathrm{Kg}$. It was concluded that the increase in the total exchangeable sodium was relatively greater in Group C than in Group B ( $p>0.05)$.

Usually the total exchangeable sodium is calculated by the dilution principle proposed by Moore. ${ }^{28\}}$ The total exchangeable sodium calculated by the extrapolation method $^{291}$ was compared with that measured by the dilution method in Fig. 8. The both values in the same subject were nearly identical with the exception of 3 cases $(r=0.986)$. All 3 patients with remarkable difference in the 2 values belonged to Group G. It was suggested that in such cases the amounts of $\mathrm{Na}^{24}$ eliminated from compartment 1 by irreversible

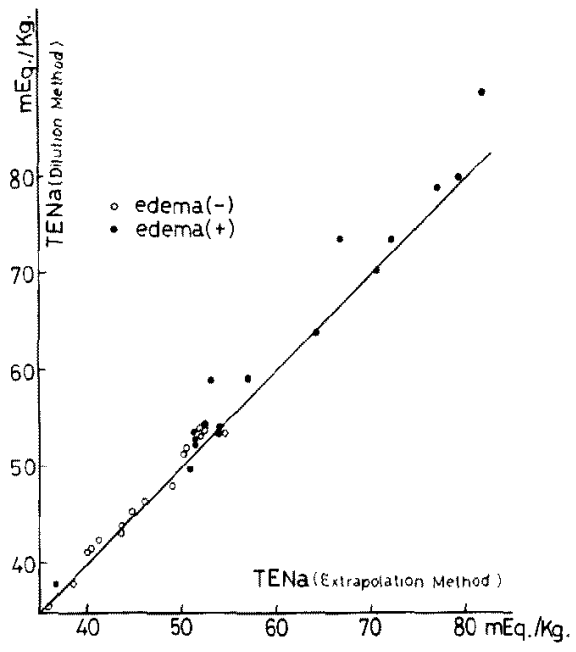

Fig. 8. Comparison of total exchangeable sodium determined by the dilution method and by the extrapolation method. 
processes were much greater than those excreted in the urine.

The rate constants for loss of $\mathrm{Na}^{24}$ from compartment 1 by irreversible processes $\left(k_{01}\right)$ were compared with the rate constants for urinary $\mathrm{Na}^{24}$ excretion $\left(\mathrm{k}_{01}{ }^{\mathrm{u})}\right)$ as shown in Fig. 9. As expected, the difference between $\mathrm{k}_{\mathbf{0 1}}$ and $\mathrm{k}_{01}{ }^{\mathrm{u}}$ ) was significantly greater in the above 3 cases than in the remainder $(\mathrm{p}>0.05)$.

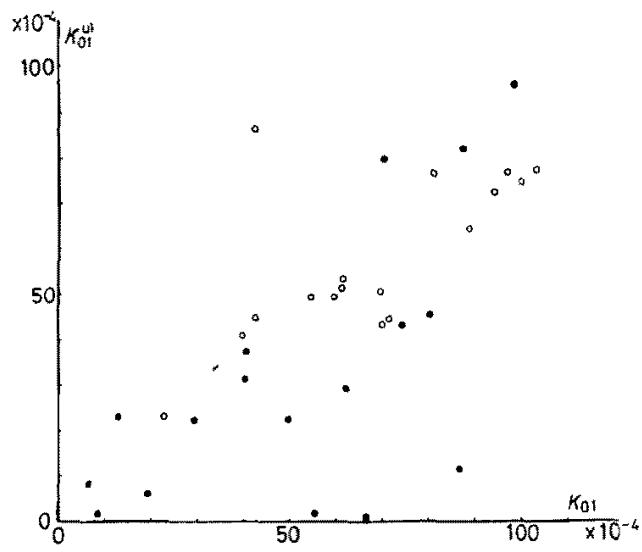

Fig. 9. Comparison between $k_{01}$ and $k_{01}{ }^{u}$ ).

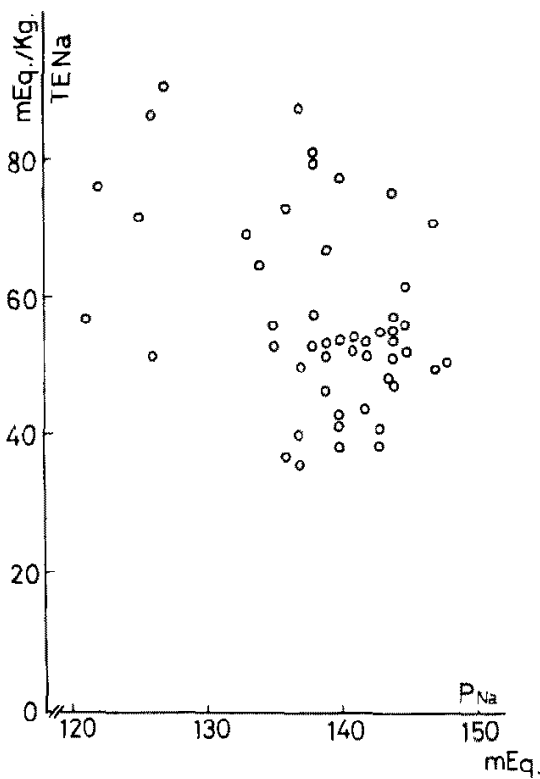

Fig. 10. Relationship between plasma scdium concentration $\left(P_{\mathrm{Na}}\right)$ and total exchangeable sodium (TENa). 
E. Relationship between plasma sodium concentration and total exchangeable sodium

Fig. 10 shows the relationship between the total exchangeable sodium per $\mathrm{Kg}$. of body weight and the plasma sodium concentration. In this figure, are included another 13 cases calculated by the dilution method besides the cases mentioned in preceding section. There was no correlation between the total exchangeable sodium and the plasma sodium concentration in the patients studied.

F. Changes in the sodium content of various compartments in edematous and uremic states

The sodium content in compartment 1, 2, and 3 for each group were expressed in mEq. per $\mathrm{Kg}$. of body weight (Table III), and they were compared with each other in Fig. 11. The mean sodium content in compartment 1 for Group A, B, and $\mathrm{G}$ were, respectively, $25.3 \pm 4.0 \mathrm{mEq} . / \mathrm{Kg}$., $27.7 \pm 4.1$ $\mathrm{mEq} . / \mathrm{Kg}$., and $43.9 \pm 9.5 \mathrm{mEq} . / \mathrm{Kg}$. Group $\mathrm{C}$ had highly increased content $(p<0.01)$, while the difference between Group A and B was not statistically significant $(p>0.1)$.

The mean sodium content in compartment 2 for each group was $7.7 \pm$ $1.6 \mathrm{mEq} . / \mathrm{Kg}$., $\quad 11.8 \pm 6.3 \mathrm{mEq} . / \mathrm{Kg}$., and $9.0 \pm 1.8 \mathrm{mEq} . / \mathrm{Kg}$., respectively. The mean value was increased slightly in Group B, although the sodium con-

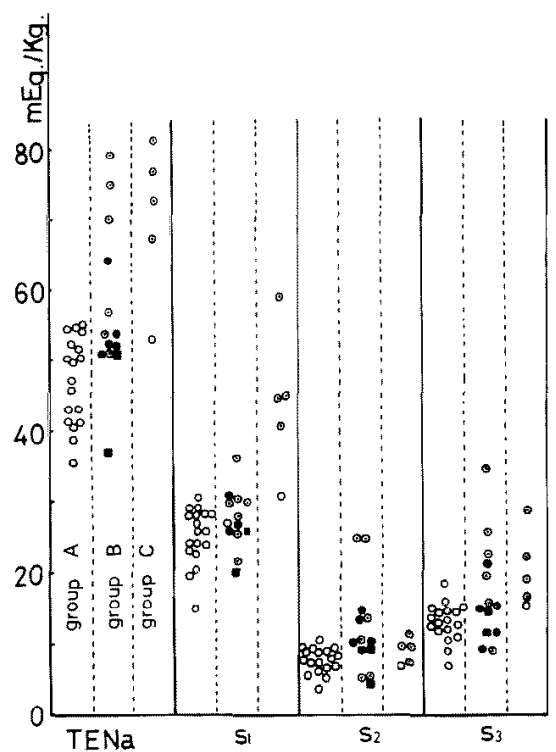

Fig. 11. The total exchangeable sodium and the sodium content in compartment 1, 2 and 3 for each group, expressed in $\mathrm{mEq}$. per $\mathrm{Kg}$. of body weight. ( $O$ edema $(-)$, ederna $(+), \odot$ ascites $(+)$.) 
tent varied considerably in the individual cases.

Those of compartment 3 for Group A, B, and C were $12.9 \pm 2.5 \mathrm{mEq} . / \mathrm{Kg}$., $17.3 \pm 7.0 \mathrm{mEq} . / \mathrm{Kg}$, , and $22.4 \pm 5.7 \mathrm{mEq} . \mathrm{Kg}$., respectively. The values in both Group B and $\mathrm{C}$ were increased significantly in comparison with that in Group $A(p<0.05, p<0.01)$. The increases were especially remarkable in patients with ascites.

It was concluded from above that in edematous and uremic states the most remarkable change was the increase in the slowly exchangeable pool, and in uremic patients the functional extracellular pool was also increased extraordinarily.

\section{Discussion}

In the present study three compartment parallel model (or mammillary model) was chosen for the kinetic model of sodium metabolism as the simplest and the fittest in explaining the experimental results.

A model is merely a conceptual tool in the analysis of sodium metabolism in the human beings. Therefore, one-to-one correspondence between a compartment and an anatomical one cannot always be expected. Furthermore, transfer rate constants are also likely to represent not a single physiological process but the average of multiple exchange processes. ${ }^{20)-25), 30)}$

As was stated previously, the first diffusion space of $\mathrm{Na}^{24}$, namely, compartment 1 was a little smaller in size than an anatomical extracellular compartment usually accepted. Walser and his coworkers termed the radiosulfate space at $18 \mathrm{~min}$. after injection as the "functional extracellular fluid ".30), 32) The word "functional extracellular fluid" seemed to be expository in this situation, and also adopted here in a slightly differing sense. Compartment 1 could be replaced with an anatomical extracellular space such that a portion of the extracellular water exists as a functional entity in which intravenously injected tracer would be mixed instantaneously. This space was termed here as the "functional extracellular space" to discriminate it from Walser's, and the difference was in that the functional extracellular space was calculated on a kinetic basis.

The volume of extracellular water is usually estimated by the dilution technique using as indicators, inulin, mannitol, sulfate, thiosulfate, radioactive sodium and so forth. ${ }^{33}$ ) However, none of these substances diffused at the same rate and in the same space within the body fluids, and it became apparent that the extracellular water available for each indicator substance was not identical. ${ }^{33)}$ Therefore, the obtained values could not be ragarded neither as an anatomical nor a functional extracellular compartment in a general sense. 
On the other hand, the space of compartment 1 in the present study will represent a functional extracellular water for sodium from a kinetic point of view. Apparently, the functional extracellular space did not include all the anatomical extracellular volume. ${ }^{31-33)}$ And consequently the remaining compartments can not be identified with definite anatomical spaces, too. It is, rather, that individual tissues or organs are composed of several small compartments with different exchange rates for sodium, and that each compartment at large may represent a sum of such parts which have the approximately same sodium exchange rates.

Kaltreider et al. $^{34}$ ) and Manery et al. $^{35)}$ have reported that the time required for tissues or organs to achieve equilibrium between radioactive and non-radioactive sodium varied considerably. Complete equilibrium was attained rapidly in the skin, kidney, liver and muscle, while in the testis, brain and bone equilibration was remarkably delayed. These findings may be explained to indicate that a large proportion of the tissues with rapid equilibration belongs to compartment 1 or 2 , and that with slow equilibration belongs to compartment 2 or 3 .

The curves representing the uptake of $\mathrm{Na}^{24}$ by the erythrocytes, ${ }^{36}$ ) which are the easily observable isolated cells, are similar to our calculated curves for $\mathrm{Na}^{24}$ activities in compartment 3 . It might be considered that the intracellular sodium was included in compartment 3. However, it was reported that sodium pool within a single erythrocyte was also not homogeneous, and that it was composed of both rapidly and slowly exchanging portions. ${ }^{36)}$ Moreover, based on the analysis of sodium kinetics there were also some evidences for the presence of more than 1 compartment within other single cell systems. ${ }^{37), 38}$ ) Therefore, it seemed to be proper to consider that the intracellular sodium was divided into compartment 2 and 3 on the basis of the sodium exchange.

It has been well known that the total body sodium was increased in edematous states. ${ }^{1-10), 16)-18), 33)}$ And it has been shown that the distribution between compartments of sodium in edematous states was different in proportion from that in non-edematous states. ${ }^{4), 8}$ ), 11, 16)-18), 33)

It was found in the present studies that even if edema or ascitic fluid existed, the compartment 1 , namely, the functional extracellular pool remained almost constant unless renal function was markedly impaired, and that the compartment 3 , the slowly exchangeable pool was markedly increased in edematous states, especially in patients with ascites.

Walser et al. ${ }^{31), 32}$ and Shires et al. ${ }^{39,40)}$ have distinguished the "functional extracellular fluid " from the total extracellular fluid.

Shires and his associates" ${ }^{40}$ showed that the "functional extracellular 
fluid" decreased after a surgical procedure, and its loss was largely due to an internal redistribution of extracellular fluid. On the contrary, Crystal et al. ${ }^{41}$ did not find on the basis of the extrapolation method that hemorrhage affected water movements into, or out of, the total extracellular fluid volume. There has been a controversy concerning the pattern of extracellular fluid volume regulation after hemorrhagic shock. However, these findings were observed in unsteady states. In any case, it was considered that the "functional extracellular fluid" occupied the physiologically active space in the total extracellular fluid. ${ }^{32,39}$

On the other hand, Shear and his colleagues ${ }^{42,43)}$ have believed that the ascitic fluid is separated in a relatively non-mobilizable compartment of extracellular fluid. Moreover, they showed that the ascites volume increased as edema diminished after paracentesis. It was considered that ascitic fluid and edema were compartmentalized besides the functional extracellular fluid. Their observations were based on the net transfer of body fluids and not on the exchange rates for the tracer. However, the apparent slow mobilizations of ascitic fluid and edema were in accord with the results mentioned previously in this report.

It might be suggested from the above facts and the present data that formation of edema and ascites would serve as a reservoir to maintain the homeostasis of the most active part of the body fluid.

A large proportion of bone sodium is reported to belong to the non-exchangeable pool, ${ }^{28,33)-35,44)}$ but it can not be quantified by the present kinetic method. The non-exchangeable sodium was thought to be a reservoir of sodium in the body in some perturbed situations. ${ }^{45)-48}$ It was also reported that the certain amounts of bone sodium was decreased in sodium deficient rats, ${ }^{45}$ and nonexchangeable sodium was mobilized. ${ }^{46)}$ On the other hand, sodium excess in the body may increase the transfer rate of sodium into the non-exchangeable pool in case of the impairment of renal sodium excretion. ${ }^{47}$ As was stated previously, there were 3 uremic patients who had much increased transfer rates into non-exchangeable pool in the 24 hour experimental period. This may be regarded as the non-exchangeable sodium pool plays at least transiently a certain role of extra-renal regulation in sodium metabolism.

\section{ACKNOWLEDGEMENT}

The author wishes to express profound thanks to Prof. Y. Yoshitoshi, Dr. Y. Araki, Dr. M. Nagasaka, and Dr. M. Kashima for their guidances, 


\section{References}

1. Threefoot, S., Bruch, G., and Reaser, P.: J. Lab. Clin. Med. 34: 1, 1949.

2. Warner, G. F., Dobson, E. L., Rodgers, C. E., Johnston, M. E., and Pace, N.: Circulation 5: $915,1952$.

3. Aikawa, J. K. and Fitz, R. H.: Circulation 12: 897, 1955.

4. Talso, P.J., Spafford, N., Ferenzi, G., and Jackson, H. O.: Metabolism 5: 58, 1956.

5. Farber, S. J. and Soberman, R. J.: J. Clin. Invest. 35: 779, 1956.

6. Duncan, L. E., Liddle, G. W., and Bartter, F. C.: J. Clin. Invest. 35: 1299, 1956.

7. Birkenfeld, L. W., Leibman, J., O'Meara, M. P., and Edelman, J. S.: J. Clin. Invest. 37: $687,1958$.

8. Carroll, H.J. and Farber, S. J.: Circulation 24: 626, 1961.

9. Flear, C. T. G., Florence, I., and Evans, D.: Brit. Heart J. 25: 166, 1963.

10. Olesen, K. H.: Acta Med. Scand. 175: 301, 1964.

11. Carroll, H. J., Gotterer, R., and Altshuler, B.: Circulation 32: 185, 1965.

12. Evens, R. G., Barer, L., Gill, J. R., Jr., and Bartter, F. G.: J. Clin. Endocr. 28: 1645, 1968.

13. Friis, T., Nielsen, B., and Willumsen, J.: Acta Med. Scand. 188: 65, 1970.

14. Landis, E. M., Jonas, L., Angevine, M., and Erb, W.: J. Clin. Invest. 11: 717, 1932.

15. Merrill, A. J.: J. Clin. Invest. 25: 389, 1946.

16. Reichsman, F. and Grant, H.: Am. Heart J. 32: 438, 1946.

17. Peters, J. P.: New Eng. J. Med. 239: 353, 1948.

18. Earley, L. E. and Daugharty, T. M.: New Eng. J. Med. 281: 72, 1969.

19. Strajman, E., Warner, G. F., Pace, N., and Johnston, M.: Acta Med. Scand. 156: 57, 1956.

20. Solomon, A. K.: Compartmental methods of kinetic analysis, Mineral metabolism, 1 (Part A), New York and London, Academic Press, 1960.

21. Ferrario, C. M., Fernández, L. A., and Mejía, R. H.: Acta Physiol. Latinoam. 18: 223, 1968.

22. Yoshitoshi, Y., Araki, Y., Nagasaka, M., Kashima, M., Miyazaki, T., Mizukoshi, H., and Kinouchi, T.: Kinetic study on sodium metabolism by compartmental analysis. SaishinIgaku 23: 2512, 1968 (in Japanese).

23. Skinner, S. M., Clark, R. E., Baker, N., and Shipley, R. A.: Am. J. Physiol. 196: 238, 1959.

24. Berman, M. and Scoenfeld, R. L.: Exp. Cell Res. 20: 574, 1960.

25. Araki, Y. and Miyazaki, T.: Jap. J. Clin. Med. 26:1277, 1968., 26: 1461, 1968., 26: 1754, 1968 (in Japanese).

26. Ralli, E. P., Robson, J. S., Clarke, D., and Hoagland, C. L.: J. Clin. Invest. 24: $316,1945$.

27. Atkinson, M. and Losowsky, M. S.: Clin. Sci. 22: 383, 1962.

28. Moore, F. D.: Science 104: 157, 1946.

29. Surveyor, I.: Am. J. Med. Sci. 256: 222, 1968.

30. Brownell, G. L., Berman, M., and Robertson, J. M.: Intern. J. Appl. Rad. Isotop. 19: $249,1968$.

31. Walser, M.: Proc. Soc. Exp. Biol. 79: 372, 1952.

32. Walser, M., Seldin, D. W., and Grollman, A.: J. Clin. Invest. 32: 299, 1953.

33. Edelman, I. S. and Leibman, J.: Am. J. Med. 27: 256, 1956.

34. Kaltreider, N. L., Meneely, G. R., Allen, J. R., and Balc, W. F.: J. Exp. Mcd. 74: 569, 1941.

35. Manery, J. F. and Bale, W. F.: Am. J. Physiol. 132: 215, 1941.

36. Solomon, A. K.: J. Gen. Physiol. 36: 57, 1952.

37. Janacek, K., Kleinzeller, A., and Knotkova, A.; J. Physiol. 162: 52, 1962.

38. Burg, M. B. and Abramow, M.: Am. J. Physiol. 211: $1011,1966$.

39. Shires, T., Williams, J., and Brown, F.: J. Lab. Clin. Med. 55: 776, 1960.

40. Shires, T., Williams, J., and Brown, F.: Ann. Surg. 154: 803, 1961.

41. Grystal, R. G. and Bauc, A. E.: Surg. Gynec. Obst. 129: 576, 1969.

42. Shear, L., Castellot, J. J., and Barry, K. G.: J. Lab. Clin. Med. 66: 232, 1965. 
43. Shear, L., Ching, S., and Gabuzda, G. J.: New Eng. J. Med. 282: 1391, 1970.

44. Forbes, C. B. and Perley, A.: J. Clin. Invest. 30: 558, 1951.

45. Bergstrom, W. H.: J. Clin. Invest. 34: 997, 1955.

46. Nichols, G., Jr. and Nichols, N.: Am. J. Physiol. 186: 383, 1956.

47. Nichols, N. and Nichols, G., Jr.: Proc. Soc. Exp. Biol. 96: 835, 1957.

48. Pellegrino, E. and Farber, S. J.: J. Lab. Clin. Med. 56: 520, 1960. 